\title{
LA PERCEPCIÓN DEL MEDITERRÁNEO A TRAVÉS DE LA INMIGRACIÓN: LAS ACTITUDES DE LOS ESPAÑOLES HACIA LOS MAGREBÍES*
}

\author{
Vicente Gozálvez Pérez
}

\section{RESUMEN}

La primera parte del estudio explica la evolución reciente (1985-95) de la inmigración magrebí en España: su incremento espectacular - 29\% anual- es resultado de flujos marcados por el acceso a España en situación irregular, pero en su mayoría estos inmigrantes fueron legalizados con motivo de las regularizaciones extraordinarias de 1985-86, 1991-92 y 1996, así como mediante los cupos o contingentes de trabajadores extranjeros no comunitarios autorizados a partir de 1993. Se destaca la importancia que en esta inmigración irregular magrebí juega la agricultura mediterránea de explotaciones minifundistas y empleo intensivo de mano de obra - aunque en tiempo discontinuo-, sobre todo para las recolecciones. En la segunda parte se comentan los principales resultados de varias encuestas realizadas en España durante los años 1990, que muestran las actitudes de los españoles hacia los inmigrantes magrebíes: este colectivo extranjero, el más numeroso en España, el de incremento más rápido y el más identificado por los españoles con inmigrante extranjero, es el que ofrece a los españoles valoración más baja, al mismo tiempo que es percibido como el más problemático para su integración en España. No obstante, tales actitudes han mejorado durante los últimos años, sobre todo entre los jóvenes y personas mejor instruidas, aunque, en cualquier caso, las encuestas muestran que los españoles parecen bastante impactados y desorientados por el cúmulo de informaciones puntuales que sobre estos extranjeros dan los medios de comunicación. Sin embargo, los españoles se muestran permisivos hacia los inmigrantes en situación irregular, actitud que también se comparte en la orientación de la política española de inmigración.

Palabras clave: Inmigración africana. Agricultura mediterránea. Actitudes hacia los inmigrantes.

* Comunicación presentada al VI Seminaire international sur «La perception de la Méditerranée par les pays méditerranées», organizado por el Comité pour les Etudes Méditerranéens; Marseille, 21-22 noviembre 1997. 


\section{RÉSUMÉ}

La première partie de l'étude explique l'évolution recente (1985-95) de l'immigration maghrebine en Espagne: son très rapide accroissement $-29 \%$ annuel-c'est fait sur les flux marqués par une arrivée à l'Espagne en situation irregulière, mais en majorité ces immigrés sont devenus en situation regulière à l'occasion des régularisations extraordinaires de 1985-86, 1991-1992 et 1996, ainsi comme au moyen de les quotas de travailleurs étrangers non communautaires autorisés à partir de 1993. On se souligne l'importance que dans cette inmigration irregulière maghrebine joue l'agriculture méditerranéenne d'exploitations minifundistes et emploi intensif de main d'oeuvre —mais à temps discontinu-, surtout pour les recoltes. Dans la seconde partie on fait le commentaire des principaux résultats de diverses enquêtes réalisées en Espagne au cours des annés 90, qui révèlent les attitudes des espagnols à l'égard des immigrés maghrebins: cet collectif étranger, le plus nombreux en Espagne, ce qui a acquis le taux de croissance la plus élevé et le plus identifié par les espagnols comme l'immigré étranger, c'est qui offre aux yeux des espagnols l'image la plus négative. Toute fois, de tels attitudes ont amélioré pendant les derniers annés, surtout parmi les jeunes et parmi les plus instruits, mais dans touts les cas, les enquêtes montrent que les espagnols paraissent assez marqués et désorientés par l'acumulation d'informations ponctuelles que sur les étrangers offrent les médias. Face à cette situation, les espagnols se montrent complaisants vers les immigrés en situation irregulière, attitude qui aussi est partagée par la politique espagnole d'immigration.

Mots Clés: Immigration africaine. Agriculture méditerranéenne. Attitudes vers les immigrés.

Durante los últimos años el crecimiento de la inmigración real y potencial desde países en vías de desarrollo ha movilizado a los gobiernos y a la opinión pública de la Unión Europea, siempre con el objetivo de controlar y disminuir tales flujos, dadas las dificultades de nuestro mercado laboral. La presión demográfica y socioeconómica crece al sur del Mediterráneo, mientras los países normediterráneos de la UE se configuran actualmente como uno de los espacios relativamente más accesibles para estos inmigrantes.

España, singularmente en su fachada mediterránea, es valorada positivamente por los norteafricanos como espacio de inmigración, a resultas de factores como la proximidad geográfica-frontera marítima o las posibilidades de trabajo en situación irregular, sobre todo en la agricultura intensiva o en servicios poco cualificados. Pese a la acentuada precariedad laboral que padecen estos inmigrantes - de acceso clandestino o irregular-, realizan tales trabajos por ser los únicos disponibles y, sobre todo, porque de hecho son la única posibilidad de acceso al trabajo reglado a través de las regularizaciones extraordinarias (1985-86, 1991-92, 1996). Tales situaciones de precariedad en los inmigrantes, combinadas con las altísimas tasas de paro que padece España, sin duda son propicias para desarrollar conflictos sociales y xenófobos, a los que se añaden, a veces, otros históricos.

En la actualidad está ampliamente aceptado que los flujos migratorios sur-norte entre países ribereños del Mediterráneo, crecerán muy notablemente en los próximos años. Por otra parte, la antigua concepción del inmigrante sólo como fuerza laboral necesaria (años sesenta), durante la actualidad ha sido sustituida por la de inmigrante-integración social, ya que los flujos norteafricanos se preveén crecientes y en su mayor parte de asentamiento definitivo en España. 
Aunque los extranjeros residentes en España con nacionalidad de paises europeos occidentales aún son el colectivo continental más numeroso - 246.295 sobre un total de 499.773 extranjeros residentes en 1995 - la atención de la sociedad española —incluidos los investigadores sociales-y las actuaciones de las Administraciones públicas españolas, siempre estuvieron centradas en la inmigración de extranjeros naturales de países en vías de desarrollo, es decir de los inmigrantes de algunos países asiáticos (de Filipinas, China) y, sobre todo, de los latinoamericanos (de Argentina, Perú, R. Dominicana,...) y de los norteafricanos, singularmente marroquíes. En efecto, estos países en vías de desarrollo tienen potencialidad casi «ilimitada» para el envío de trabajadores y de reagrupantes familiares, mientras en España se padece grave crisis de empleo; el paro existente - además de otras razones sociales - es primordial para explicar las actuales políticas sobre inmigración extranjera, pues resulta evidente la competencia entre inmigrados y nacionales poco cualificados sobre el mercado del empleo, sobre todo a partir de la regularización del inmigrante.

Las políticas y los documentos gubernamentales, las encuestas de opinión de los españoles, así como los hechos mostrados diariamente en los medios de comunicación, coinciden en prever una continuidad creciente de la inmigración extranjera en España, igual que para el resto de Europa occidental. En la actualidad el flujo marroquí es el que muestra tasas de incremento más espectaculares y el que alcanza implantación geográfica más extensa sobre el territorio español, especialmente en las áreas con economía más dinámica (Madrid y litoral mediterráneo entre Almería y Girona). Así, mientras los latinoamericanos (92.646 residentes en 1995) se concentran mucho en las aglomeraciones de Madrid y de Barcelona (54\% del total), los africanos (95.725 residentes en 1995) se distribuyen, además de en las dos metrópolis indicadas (38\%), por todo el litoral mediterráneo. Esta distribución litoral de los africanos está asociada tanto a imperativos del desarrollo económico español, como a la situación geográfica respecto a su acceso a España, pues las «puertas» de llegada se sitúan en las costas del Estrecho de Gibraltar (para las «pateras» que llegan clandestinamente) y en los puertos de Algeciras, Málaga, Almería y Alicante; Barcelona y su entorno son, desde los años 1970, la primer área española receptora de magrebíes.

El carácter itinerante, inestable y con frecuencia irregular de los empleos que suelen ocupar los magrebíes, contribuye decisivamente a alimentar la segregación y exclusión sociales que con frecuencia padece este colectivo. Esto se explica por su inicial situación irregular en España, el difícil mercado laboral e incluso las actitudes de los españoles hacia ellos, según se desprende de las encuestas.

Así, la percepción y actitud de los españoles sobre la creciente comunidad magrebí inmigrada en España, se encuentran actualmente en niveles no satisfactorios; esto se pretende corregir con políticas de integración más activas, mientras las actitudes de los españoles parece que evolucionarán positivamente a juzgar por las favorables predisposiciones que muestran los encuestados menores de treinta años de edad y los más instruidos.

La inmigración magrebí ha alcanzado durante los últimos años indiscutible protagonismo en la opinión pública española. Este hecho es sin duda un indicador esencial para valorar cómo las sociedades mediterráneas perciben uno de los aspectos actuales sin duda más problemáticos, como es la necesaria cooperación para la comprensión y el desarrollo entre los países del norte y los del sur. El seguimiento de las actitudes o valoraciones que muestran los españoles sobre estos inmigrantes puede ser interpretado, por una parte como barómetro que señala posibilidades reales de integración social para los inmigrantes que ya residen en España, en la actualidad con problemas de aceptación e integración, y, por otra, pueden proporcionar información útil para seleccionar medidas y políticas que ayu- 
den a desarrollar, a ambos lados del Mediterráneo, acciones y mentalidades que faciliten la cooperación para un desarrollo común.

El texto que presentamos incluye dos partes. En la primera se muestra la «realidad» de la inmigración reciente en España, fundamentalmente en lo que concierne a los magrebíes; en la segunda parte se comentan los principales resultados de varias encuestas realizadas en España durante los años 1990, que muestran las actitudes de los españoles hacia los inmigrantes magrebíes.

\section{La inmigración magrebí en España: un flujo con incremento acelerado, marcado por su llegada en situación irregular y con problemas de integración social}

Entre 1985 y 1995 los extranjeros residentes en España han doblado sus efectivos, al pasar de 242.000 a 500.000, lo que supone incremento anual de 7'5\% (cuadro 1). Aunque los extranjeros originarios de países desarrollados aún son los mayoritarios -264.000 en 1995-, los inmigrantes que tienen nacionalidad de países en vías de desarrollo han aumentado con tasas tres veces superiores, es decir 4'4\% anual los primeros frente a $12{ }^{\prime} 9 \%$ los segundos. El incremento de los magrebíes residentes en España destaca sobre cualquier otro colectivo, pues su tasa en el periodo indicado ha sido del 28 ' $8 \%$ anual, es decir 6.268 en 1985 y 78.893 en 1995, de los que 75.000 son marroquíes; esta nacionalidad ya es la más numerosa entre los extranjeros residentes en España, y como en otros países europeos de inmigración, los marroquíes son el colectivo extranjero de mayor incremento ${ }^{1}$. Además, el protagonismo marroquí se acentúa sobremanera si contabilizamos sólo a los trabajadores, pues de los 139.038 extranjeros de países distintos a los de la U.E. que tienen permiso de trabajo en España a 31-12-1995, 51.624 (37\%) son marroquíes, mientras los peruanos, segunda nacionalidad en número de trabajadores, sólo contabiliza 11.368 y 43.521 todos los latinoamericanos ${ }^{2}$.

Aunque la presencia de magrebíes en España se incrementa con rapidez desde principios de los años 1980, la incorporación de estos inmigrantes a las estadísticas oficiales españolas se acentúa con ocasión de las regularizaciones extraordinarias de extranjeros de 1985-86, 1991-92, y 1996, pues su llegada se realizó generalmente en situación irregular. Además, desde 1993, la autorización de cupos o contingentes anuales de trabajadores extranjeros no comunitarios, también benefician de modo destacado al incremento de magrebíes en España (cuadro 2).

En efecto, mientras la estadística oficial de 1984 recogía en España 5.616 magrebíes, la regularización extraordinaria de 1985-86 fue solicitada por 7.868 marroquíes, 116 argelinos y 35 tunecinos, que suman el $18 \%$ de un total de 43.815 solicitudes de regularización. En 1990 los magrebíes en situación regular eran 17.670, mientras los que solicitaron ser regularizados en 1991 se elevaron a 58.307 marroquíes, 5.147 argelinos y 247 tunecinos, que suman el $47 \%$ de un total de 134.905 solicitudes. La entrada en vigor en 1996 del nuevo Reglamento de ejecución de la Ley Orgánica 7/1985 — Ley de Extranjería—, de facto ha constituido la tercera regularización extraordinaria, con 25.388 solicitudes (hasta

1 BARSOTTI, O., et al., Dal Marocco in Italia, Milano, edit. Franco Angelí, 1994, 229 pp.

GOZÁLVEZ PÉREZ, V., «La inmigración magrebí en Europa. El caso de España», Polígonos. Revista de Geografía, no 3, Universidad de León (España), 1993, pp. 59-87.

2 Comisión Interministerial de Extranjería, Anuario estadístico de extranjería 1995, Madrid, Ministerio de Justicia e Interior, Secretaría General Técnica. 
Cuadro 1

NÚMERO DE RESIDENTES EXTRANJEROS EN ESPAÑA (A 31-XII)

\begin{tabular}{|c|c|c|c|c|}
\hline Origen & 1985 & 1992 & 1995 & $\begin{array}{l}\text { Var. Anual } \\
\text { 1992-95, \% }\end{array}$ \\
\hline Europa & 158.211 & 196.984 & 255.702 & 9'1 \\
\hline$\%$ & $65^{\prime} 4$ & $50 ' 1$ & $51^{\prime} 2$ & \\
\hline CEE (12) & 142.227 & 173.140 & 224.965 & 9'1 \\
\hline Rest. Eur. Occ. & 15.213 & 16.953 & 21.330 & $8^{\prime} 0$ \\
\hline Europa Est & 711 & 6.891 & 9.407 & $10^{\prime} 9$ \\
\hline$\underline{\text { USA + Canadá }}$ & 13.281 & 15.477 & 16.289 & $1^{\prime} 7$ \\
\hline$\%$ & $5^{\prime} 5$ & 3'9 & 3'3 & \\
\hline Oceanía & 748 & 736 & 859 & $5^{\prime} 3$ \\
\hline América Latina & 40.796 & 73.823 & 92.642 & 7'9 \\
\hline$\%$ & $16^{\prime} 9$ & $18^{\prime} 8$ & $18^{\prime} 5$ & \\
\hline$\underline{\text { Asia }}$ & 19.366 & 33.878 & 38.221 & 4'1 \\
\hline$\%$ & $8^{\prime} 0$ & $8^{\prime} 6$ & $7^{\prime} 6$ & \\
\hline África & 8.529 & 71.292 & 95.725 & $10 ' 3$ \\
\hline$\%$ & $3 ' 5$ & 18'1 & 19'2 & \\
\hline Marruecos & 5.817 & 54.105 & 74.886 & $11^{\prime} 4$ \\
\hline Apátridas & 1.039 & 910 & 335 & $-23 ’ 2$ \\
\hline Total & 241.971 & 393.100 & 499.773 & 8,3 \\
\hline
\end{tabular}

Fuente: Ministerio del Interior. Dirección General de la Policía, Memoria anual. Comisión Interministerial de Extranjería, Anuario Estadístico de Extranjería 1993 y 1995.

el 11-11-1996), de los que el 40\% son magrebíes. Finalmente, los cupos o contingentes de trabajadores extranjeros no comunitarios, entre 1993 y 1995 han autorizado la regularización de 50.770 trabajadores, de los que 18.391 -36'2\% — han sido magrebíes (16.902 marroquíes, 1.464 argelinos y 25 tunecinos) $)^{3}$.

Estas elevadas cifras —en valor absoluto y relativo- de solicitudes de regularización denuncian, pues, el generalizado y continuado acceso irregular de los magrebíes que llegan a España: así, en 1991, entre los marroquíes se contabilizan 350 solicitudes de regularización por cada 100 residentes en situación regular; por contra, dicha proporción baja a

3 Dirección General de Migraciones, Informe estadístico de regularización hasta el 31 de diciembre de 1993 (mecanografiado).

ARAGÓN BOMBÍN, R.; CHOZAS PEDRERO, J., La regularización de inmigrantes durante 1991-1992, Madrid, Ministerio de Trabajo y Seguridad Social, 1993, 471 pp. Cfr. p. 101.

Ministerio del Interior. Dirección General de la Policía. Comisaría General de documentación, Memoria, 1985, 1986, 1990.

Ministerio de Trabajo y Asuntos Sociales, Anuario de Migraciones 1996, Madrid. 
Cuadro 2

CONTINGENTES AUTORIZADOS DE TRABAJADORES EXTRANJEROS NO COMUNITARIOS

\begin{tabular}{|c|c|c|c|c|c|c|c|c|c|}
\hline Año & Contingente & Solicitudes & \multicolumn{7}{|c|}{ Permisos de trabajo concedidos } \\
\hline & & & Agricultura & Construcción & $\begin{array}{c}\text { Empleadas } \\
\text { de hogar }\end{array}$ & $\begin{array}{c}\text { Otros } \\
\text { servicios }\end{array}$ & Total & Magreb & $\%$ \\
\hline 1993 & 20.600 & 6.000 & 160 & & 4.346 & 714 & 5.220 & 597 & $11^{\prime} 4$ \\
\hline 1994 & 20.600 & 37.277 & 8.453 & 737 & 13.728 & 2.686 & 25.604 & 10.808 & $42 ’ 2$ \\
\hline 1995 & 25.000 & 37.214 & $7.855^{*}$ & & & $12.091^{*}$ & $19.946^{*}$ & 6.986 & $35^{\prime} 0$ \\
\hline 1997 & 24.690 & distribució & 9.700 & 1.000 & 9.090 & 4.900 & 25.000 & & \\
\hline
\end{tabular}

* Datos provisionales a 13-XI-1996.

Fuente: Ministerio de Trabajo y Asuntos Sociales, Anuario de Migraciones 1996.

Para 1997, B.O.E. de 5-02-1997 y Consejo de Ministros de 7-11-1997. 
Cuadro 3

NÚMERO DE TRABAJADORES EXTRANJEROS EN ESPAÑA (A 31-XII)

\begin{tabular}{|c|c|c|c|c|}
\hline Origen & 1990 & 1992 & 1995 & $\begin{array}{l}\text { Var. Anual } \\
\text { 1992-95, \% }\end{array}$ \\
\hline$\frac{\text { Europa }}{\%}$ & 40.141 & $9.922 *$ & $\begin{array}{r}7.004 * \\
5{ }^{\prime} 0\end{array}$ & $-11^{\prime} 0$ \\
\hline$\frac{\text { USA + Canadá }}{\%}$ & 3.720 & 3.504 & $\begin{array}{r}2.447 \\
1 ' 8\end{array}$ & $-11 ' 3$ \\
\hline Oceanía & 166 & 176 & 121 & $-11^{\prime} 7$ \\
\hline$\frac{\text { América Latina }}{\%}$ & 16.952 & 38.403 & $\begin{array}{r}43.499 \\
31 ' 3\end{array}$ & $4^{\prime} 2$ \\
\hline$\frac{\text { Asia }}{\%}$ & 11.294 & 20.326 & $\begin{array}{r}20.613 \\
14 ' 8\end{array}$ & $0^{\prime} 5$ \\
\hline$\frac{\underline{\text { África }}}{\%}$ & 12.884 & 66.884 & $\begin{array}{r}65.223 \\
46,9\end{array}$ & -0 '8 \\
\hline $\begin{array}{c}\text { Marruecos } \\
\%\end{array}$ & 8.844 & 52.501 & $\begin{array}{r}51.624 \\
37 ' 1\end{array}$ & $-0 ' 6$ \\
\hline Apátridas & 175 & 206 & 131 & $-14^{\prime} 0$ \\
\hline$\underline{\text { Total }}$ & 85.372 & 139.421 & 139.038 & -0'09 \\
\hline
\end{tabular}

* Excepto U.E.

Fuente: Ministerio de Trabajo: Estadística de permisos de trabajo a extranjeros (anual).

50 entre los latinoamericanos y a 53 entre los asiáticos. Así, los magrebíes son los protagonistas destacados de la inmigración irregular en España, a donde accedieron bien de forma clandestina ${ }^{4}$, bien como turistas, pero reconvertidos después a trabajadores y/o residentes ilegales ${ }^{5}$, a la espera de una regularización extraordinaria.

Una serie de factores hace que los españoles asocien ampliamente el colectivo magrebí con el conjunto de los inmigrantes: así, los magrebíes representan el 16\% de todos los extranjeros que residen legalmente en España, pero pasan a representar el $68 \%$ cuando los

4 El acceso clandestino de inmigrantes africanos por vía marítima, se efectúa mediante: a) pateras o pequeñas embarcaciones que transportan hasta 20 personas, son de poco fondo y motor fuera borda, lo que facilita su acceso a las playas españolas, fundamentalmente en la provincia de Cádiz, a donde llegan procedentes de la costa marroquí entre Ceuta y Tánger; b) en barcos de pesca españoles; c) ocultos en vehículos transportados en los ferrys, que llegan a los puertos españoles de la costa andaluza, fundamentalmente al de Algeciras; d) como polizones, que acceden a barcos fondeados en los puertos de Ceuta, de Melilla o incluso en puertos marroquíes.

5 Este proceso es confirmado en informes de autoridades españolas, y sobre todo en la encuesta realizada por el Ministerio de Trabajo a 4.780 trabajadores magrebíes regularizados en 1991: el $87 \%$ declara que entró en España como turista, y sólo el 4'4 \% con visado para trabajar. Ministerio de Trabajo y Seguridad Social, Encuesta cualitativa sobre inmigrantes regularizados (mecanografiado). 
españoles asocian inmigrantes extranjeros y nacionalidad de los mismos (CIS, 1995, P14) ${ }^{6}$. Entre dichos factores podemos destacar la intensidad del incremento de los inmigrantes magrebíes en España; las llamativas penurias laborales, de vivienda, ... etc. que conlleva su inicial situación irregular en España; su destacada vinculación con la delincuencia menor $^{7}$ (a veces «necesaria» por motivos de supervivencia), bien conocida a través de la prensa $^{8}$; así como los frecuentes reportajes que ofrecen los medios de comunicación sobre las difíciles condiciones de vida y de trabajo que soportan estos inmigrantes, tanto en habitat urbano como rural, sobre los apresamientos de pequeñas embarcaciones o «pateras» cargadas de inmigrantes en las costas del Estrecho de Gibraltar, o sobre el final trágico que tienen algunas de estas travesías marítimas.

Durante los últimos años, después que han sido depuradas y mejoradas las estadísticas sobre extranjeros en España, es preciso resaltar el diferente ritmo de incremento entre residentes y trabajadores magrebíes en España. Así, mientras estos residentes se han incrementado con tasa de 11'4\% anual entre 1992 y 1995 (cuadro 1), los trabajadores magrebíes en situación regular han experimentado una ligera disminución (-0’6\% anual) (cuadro 3). Dadas las características demográficas y sociolaborales de los inmigrantes norteafricanos ${ }^{9}$, este diferente ritmo de crecimiento entre residentes y trabajadores parece denunciar la formación continuada de bolsas de trabajadores en situación irregular, que se acumulan mayoritariamente entre los que trabajan en el sector agrario.

En efecto, si las costas próximas al estrecho de Gibraltar $^{10}$ forman para la inmigración una «puerta» geográfica de uso internacional, en el litoral mediterráneo de España se ha formado otra «puerta» para los inmigrantes africanos, ésta ligada al empleo, la del trabajo - en situación irregular o no- en las explotaciones agrícolas intensivas de tipo familiar y minifundista. Los trabajadores extranjeros en el sector agrario español son oficialmente $20.000-14 \%$ del total- en 1995, aunque según las encuestas este sector continúa registrando un elevado número de inmigrantes en situación irregular, permanentemente reno-

6 En este trabajo se utilizan: a) Encuestas del CIS (Centro de Investigaciones Sociológicas, Madrid) realizadas en 1990, «Inmigración y racismo» (II), 17.687 entrevistas; en 1993, «Actitudes ante la inmigración», 2.499 entrevistas; y en 1995, «Actitudes ante la inmigración», 3.991 entrevistas; todas estas encuestas son de ámbito nacional, y su universo población española de ambos sexos de 18 y más años de edad.

b) Encuestas del CIRES (Centro de Investigaciones sobre la Realidad Social, Madrid) «Actitudes hacia los inmigrantes», fueron realizadas en marzo de 1991, 1992, 1993, 1994 y 1995 (en marzo y octubre); cada una de ellas incluye una muestra de 1.200 personas de uno y otro sexo, de 18 y más años de edad, residentes en España; las entrevistas se realizaron en el hogar del entrevistado; Director, Prof. Juan Díez Nicolás.

c) GOZÁLVEZ PÉREZ, V. (Dir.), Inmigrantes marroquíes y senegaleses en la España mediterránea, Valencia, Generalitat Valenciana, Conselleria de Treball i Afers Socials, 1995, 440 pp. Esta investigación está basada en 498 encuestas a inmigrantes marroquíes y en 108 a senegaleses residentes en las ocho provincias litorales entre Girona y Almería; la encuesta se realizó entre 1991 y 1993.

7 En efecto, en 1994 los marroquíes y argelinos representan, respectivamente, el 13'9 y 0'7\% de todos los extranjeros residentes en España, pero han protagonizado el 26'2\% y 23'9\% de todos las detenciones policiales -55.866 - efectuadas sobre los extranjeros; vid. GOZÁLVEZ PÉREZ, V., «L'Immigration africaine en Espagne: l'entrée par la frontière meridionale», Crescita demografica e migrazioni internazionali nel bacino mediterraneo, Quaderni 11, Bari, Università degli Studi, Dipartimento per lo studio delle società mediterranee, Cacucci Editore, 1996, pp. 123-141.

8 GOZÁLVEZ PÉREZ, V. (Dir.), Inmigirantes marroquíes y senegaleses en la España mediterránea, Valencia, Generalitat Valenciana Conselleria de Treball i Afers Socials, 1995, 440 pp. Cf. pp. 387-442, «Noticias sobre inmigrantes marroquíes y senegaleses en los diarios La Vanguardia (Barcelona), Mediterráneo (Castellón), Levante (Valencia) e Información (Alicante)».

9 GOZÁLVEZ PÉREZ, V. (dir.), Inmigrantes marroquíes y senegaleses en la España mediterránea, op. cit.

10 GOZÁLVEZ PÉREZ, V., «L'immigration africaine en Espagne: l'entrée par la frontière meridionale», op. cit. 
$\operatorname{vados}^{11}$. Los africanos ocupan el $96 \%$ de estos empleos agrarios, distribuidos fundamentalmente en la fachada mediterránea de España, sobre todo en Cataluña, Murcia y Almería, dedicados a explotaciones familiares y minifundistas, tanto hortícolas - con frecuencia bajo abrigo plástico- como frutícolas, que demandan mano de obra abundante pero concentrada en el tiempo, sobre todo para la recolección.

La llegada continua de norteafricanos en busca de trabajo en la agricultura, único sector —además del servicio doméstico — donde actualmente tienen cierta posibilidad de encontrar empleo en España, provoca sobre oferta de mano de obra, lo que unido a la estructura familiar y minifundista de las explotaciones agrícolas, y a la demanda estacional y/o discontinua de estos trabajadores, origina en ellos importantes desplazamientos — sobre todo de los inmigrantes recién llegados- según los calendarios agrícolas ${ }^{12}$. Los enclaves agrícolas objeto de estas migraciones circulares, se localizan en el arco Mediterráneo y Valle del Ebro. Tales sistemas de empleo agrícola, discontinuos en el tiempo, con frecuencia itinerantes, y con sobre oferta de trabajadores, provocan ganancias insuficientes y condiciones de vida negativas para el éxito del proyecto migratorio de estos jornaleros. Pese a las dificultades, según las encuestas, la mayoría de estos trabajadores planifican su permanencia definitiva en España, acompañada de reagrupamiento familiar, eso sí, como trabajadores en sector económico distinto al agrícola. Así, para los inmigrantes magrebíes, esta oferta de trabajo agrícola ocasional es utilizada como «puerta de acceso» a España y, una vez regularizada su situación laboral, como medio de acceso a otros sectores de actividad más apetecidos.

Por otra parte, este trabajo agrícola ocasional, por su misma estructura productiva, continuará reclamando nuevos inmigrantes, pues tales trabajos discontinuos y con frecuencia itinerantes, no suelen ser aceptados por los asalariados españoles pero sí por los inmigrantes africanos recién llegados, pues su frecuente situación irregular es una barrera para el acceso a puestos de trabajo en otros sectores económicos. El frecuente origen urbano de los inmigrantes magrebíes y las negativas repercusiones económicas y de superación laboral y social que conlleva esta actividad agrícola, explican el generalizado rechazo del inmigrante al trabajo agrícola — confesado en las encuestas - y el apetecido cambio a empleos secundarios o terciarios ${ }^{13}$.

\section{Las actitudes de los españoles hacia los inmigrantes magrebíes}

El conjunto de los extranjeros representa en 1995 sólo el 1'3\% de la población española, la proporción más baja — junto con la de Finlandia— entre todos los países de la

11 NARBONA REINA, L.M., Marroquies en Viladecans. Una aproximación al tema de la inmigración. Ajuntament de Viladecans, 1993, 193 pp.

AVELLÁ REUS, L., «Competencia y complementariedad en el mercado de trabajo entre nacionales e inmigrantes: el caso español», in Seminario Inmigración, empleo e integración social, Universidad Menéndez Pelayo, Santander, 1995, 31 pp. (mecanografiado).

GOZÁLVEZ PÉREZ, V. (dir.), Inmigrantes marroquíes y senegaleses en la España mediterránea, Generalitat Valenciana, Conselleria de Treball i Afers Socials, Valencia, 1995, 440 pp.

CHECA, F., Invernaderos e inmigrantes: el problema de la adaptación de un colectivo marginal, D.G. de Migraciones, Madrid, 1994, 70 pp. (mecanografiado).

12 GOZÁLVEZ PÉREZ, V. y LÓPEZ TRIGAL, L., «Jornaleros extranjeros en el campo español», Ería, (en prensa).

13 GOZÁLVEZ PÉREZ, V. (dir.), Inmigrantes marroquíes y senegaleses en la España mediterránea, op. cit. 
Unión Europea ${ }^{14}$; si nos referimos sólo a los 79.000 magrebíes — 16\% de los extranjerostal proporción baja al 0’2\%. No obstante $-\mathrm{y}$ a efectos de percepción-, la distribución geográfica de los norteafricanos ofrece presencias relativas contrastadas, que los hace mucho más visibles en espacios reducidos del litoral mediterráneo, bien sea en barrios del centro de algunas ciudades o en comarcas de agricultura muy intensiva; además, la percepción de los magrebíes también resalta por su continuo protagonismo en los medios de comunicación, con noticias de variado signo. Como resultado, la percepción que muestran los españoles de los extranjeros ${ }^{15}$ se concentra mayoritariamente en los magrebíes, pues el $68 \%$ de los españoles asocia extranjero con magrebí.

Por otra parte, la asociación de inmigrante con procedencias de países no desarrollados es total, pues aunque los europeos representan de hecho más de la mitad de los extranjeros residentes en España, sólo el $2 \%$ de los encuestados cree que estos son los más numerosos, frente al $58 \%$ que otorgan la primacía del número a los magrebíes.

Aunque, como se ha dicho, los extranjeros en España representan una proporción muy baja, casi un tercio de los españoles opina que aquéllos ya son demasiados, y que, además, en los próximos años aumentarán mucho (29\%), lo que es malo para el $21 \%$ de las personas encuestadas, aunque esta valoración negativa se reduce a menos de la mitad entre los menores de 30 años de edad. Por otra parte, los españoles parecen bastante impactados y desorientados por el cúmulo de informaciones puntuales sobre extranjeros, pues, pese a lo reciente de la inmigración en España, el 30\% de los encuestados cree que aquí hay igual o más inmigrantes que en Francia o Alemania.

Si los magrebíes son para los españoles los extranjeros por antonomasia, y además es el colectivo con mayor tasa de incremento, cobra especial relevancia la valoración o simpatía que hacia ellos muestran los españoles. Para los encuestados, los magrebíes son los extranjeros con valoración más baja: en escala de 0 a 10 (muy bien valorado), el $22 \%$ de los españoles sitúa a los magrebíes con calificaciones negativas ( 0 a 4$)-11 \%$ en el caso de los africanos de raza negra, $8 \%$ en el de los sudamericanos- No obstante, en la serie de encuestas del CIRES la valoración se corrige positivamente, pues de una puntuación media de 4'9 otorgada en 1991, se sube a 5'7 en 1995 — con máximo de 6' 6 para europeos y sudamericanos-, aunque los avances son muy lentos cara al futuro, a juzgar por la escasa diferencia que en esta valoración muestran las menores de 30 años de edad - 5'9y los mayores de 65 años - 5'7—. Además, la valoración real parece que se deteriora ostensiblemente cuando se produce concentración local de magrebíes, tanto en medio urbano como en las áreas de empleo agrícola, lo que ha sido especialmente constatado en la agricultura intensiva de la provincia de Almería ${ }^{16}$. La discriminación que provoca la con-

14 SOPEMI, Tendances des migrations internationales. Rapport annuel 1994, OCDE, París, 1995, 253 pp. Cfr. p. 204.

15 Salvo indicación contraria, las encuestas a las que se hace referencia son las de 1995, (ver nota 6).

16 CHECA, F., Invernaderos e inmigrantes: el problema de la adaptación de un colectivo marginal, D.G. de Migraciones, Madrid, 70 pp. (mecanografiado).

GOZÁLVEZ PÉREZ, V. y LÓPEZ TRIGAL, L., «Jornaleros en el campo español», Ería, (en prensa).

GOZÁLVEZ PÉREZ, V. (dir.), Inmigrantes marroquíes y senegaleses en la España mediterránea, Generalitat Valenciana, Conselleria de Treball i Afers Socials, Valencia, 1995, 440 pp.

PONCE HERRERO, G.; VALERO ESCANDELL, J.R.; PALAZÓN FERRANDO, S., «Marroquíes en Cataluña. Estrategias selectivas de integración: la gran ciudad, los núcleos industriales y los municipios menores», Boletín de la Asociación de Geógrafos Españoles, no 23, 1996, pp. 151-167.

SEGRELLES SERRANO, J.A.; GOMEZ LOPEZ, J.D., «Agricultura intensiva y mano de obra marroquí en el Campo de Dalías (Almería)», Boletín del Instituto de Estudios Almerienses. Letras, nº 14, 1995, pp. 155-172. 
centración de inmigrantes es, además, bien percibida por los encuestados (CIRES), ya que el $69 \%$ opina que tal concentración en barrios determinados dificulta su integración, proporción que sube hasta el $78 \%$ para los menores de 30 años de edad. En consecuencia, el $56 \%-66 \%$ entre menores de 30 años de edad- opina que el Gobierno debería practicar una política de dispersión de los inmigrantes en diferentes barrios.

Otro indicador significativo sobre la deficiente valoración que los españoles muestran respecto a los magrebíes, es el grado de molestia que provocaría tenerlos como hipotéticos vecinos: molestarían a un $13 \%$ de los encuestados, frente al $10 \%$ en el caso de africanos de raza negra o al $8 \%$ en el de los sudamericanos; además el grado de molestia apenas si varía entre 1991 y 1995. En cualquer caso, siempre son los menores de 30 años de edad y los que tienen ideología de izquierda, los que muestran indicadores más favorables respecto a los inmigrantes. De hecho, estos inmigrantes encuentran gravísimas dificultades en la búsqueda de viviendas, por lo que en fuertes proporciones se ven obligados a habitar en infraviviendas ${ }^{17}$, lo que a su vez dificulta gravemente las posibilidades de su integración social.

La discriminación hacia el inmigrante parece que se endurece cuando el encuestado enjuicia la actitud hacia los inmigrantes que tienen sus amigos y conocidos, y sobre todo los españoles en general: tendrían actitud negativa hacia el inmigrado el $21 \%$ de los amigos y conocidos del encuestado, y el 55\% de los españoles en general, aunque en ambos casos la actitud percibida por el encuestado en 1995 ha mejorado respecto a 1992 (cuando dichas proporciones eran $28 \%$ y $62 \%$, respectivamente).

Para los españoles encuestados, los motivos que conducen a la emigración son fundamentalmente de necesidad económica (58\%), creencia que aumenta ligeramente entre 1991 y 1995, y en la que insisten más los menores de 30 años de edad; en el caso de España la experiencia muestra que esta percepción responde plenamente a la realidad. Por ello, la solidaridad de los españoles parece resentirse, pues el 56\% de los encuestados se declara partidario de limitar la entrada en España de estos inmigrantes, proporción que varía poco entre los diversos grupos de edad o de posición social.

Entre las medidas de control de entrada de inmigrantes, los encuestados respaldan notablemente las practicadas en la actualidad: como medidas más eficaces (primera y segunda medida propuestas), el $42 \%$ se declara partidario de sanciones penales a los que transportan inmigrantes indocumentados; el $34 \%$ son favorables a las multas a los que emplean en condiciones irregulares a los inmigrantes; el 32\% es partidario de la fijación del cupo anual de trabajadores, vigente desde 1993, aunque un tercio opina que aquél es demasiado generoso; el 31\% destaca la necesidad de visado para entrar en España y el 26\% subraya la vigilancia en el Estrecho de Gibraltar. Todas las medidas indicadas están de facto ampliamente relacionadas con la inmigración magrebí, que, según vimos, es la que más se caracteriza por los inmigrantes en situación irregular.

La integración de los inmigrantes magrebíes es, según los españoles encuestados, la más difícil entre todas las procedencias: el $60 \%$ opinan que es problemática (CIRES), aunque en la encuesta del CIS se otorga tal primacía a los africanos de raza negra $(61 \%)$, seguidos de marroquíes (39\%), conclusión que es compartida en las encuestas realizadas a marroquíes y senegaleses en la fachada mediterránea de España. De hecho los españoles encuestados por CIRES han conversado más con los marroquíes $(25 \%)$ que con los afri-

17 GOZÁLVEZ PÉREZ, V. y LÓPEZ TRIGAL, L., «Jornaleros en el campo español», Ería, (en prensa). 
canos de raza negra (20\%), conversaciones que en un $24 \%$ de los casos sirvieron para mejorar la imagen que el ciudadano español tenía sobre estos inmigrantes. Además, el parentesco-amistad con los africanos es aún muy débil — 6\% de los encuestados-, y más aún el contacto en el trabajo, pues sólo el $4 \%$ de los encuestados lo ha tenido con los norteafricanos.

No obstante, los graves problemas para la integración de los inmigrantes que los encuestados dicen detectar, parece que no los han verificado plenamente, pues tres de cada cuatro encuestados apenas si tienen inmigrantes en su vecindario, y sólo un 3' $6 \%$ ha tenido noticia de que inmigrantes de países menos desarrollados han provocado problemas de convivencia en el barrio en que viven (CIRES). Estos problemas están referidos fundamentalmente a drogas, delincuencia-robos y peleas; a formar esta opinión tal vez ha contribuido involuntariamente —como en otros aspectos relacionados con estos inmigrantes - la prensa local-provincial, que suele publicar abundantes noticias sobre la delincuencia atribuida a estos inmigrantes. Todo lo indicado conduce a que los encuestados sólo en muy escasa proporción —un 4\% - darían preferencia a los marroquíes a la hora de facilitar la permanencia de los inmigrantes en España —el 27\% la daría a los latinoamericanos y el $5 \%$ a los africanos de raza negra-.

Tal como indican las estadísticas de los que en su momento solicitaron regularización (1985, 1991, 1996), los magrebíes forman las mayores bolsas de inmigrantes en situación irregular en España, que además se renuevan constantemente. Ante esta situación, la opinión de los españoles encuestados se muestra condescendiente: el 60\% (CIS) cree que se les debería regularizar, aunque, según las encuestas del CIRES, tal decisión debe ser matizada: la cuarta parte de los encuestados opina afirmativamente, sin más; mientras el resto de los que postulan la regularización —otro 54\% de los encuestados — la condiciona a que el inmigrante esté trabajando (19\%) o pueda trabajar en un plazo de tres meses (35\%), y en caso contrario, estos últimos se sumarían al $17 \%$ de los encuestados que opinan que a los inmigrantes irregulares se les debe repatriar o expulsar de España. La actitud permisiva respecto a la permanencia en España de los inmigrantes en situación irregular, se acompaña de la voluntad de facilitarles amplio acceso a los servicios más fundamentales, como escuela pública para los niños $(61 \%)$ o los servicios de salud pública $(67 \%)$, así como proporcionarles otros medios fundamentales para su futura integración, como son formación profesional (55\%), cursos de idioma español (59\%) y vivienda (47\%).

Aunque el $60 \%$ de los españoles encuestados (CIS) dice estar de acuerdo con el establecimiento del cupo anual para trabajadores extranjeros ofertado desde 1993, los empleos para los que se suele establecer tal cupo — trabajadores para la agricultura y servicio doméstico- son escasamente valorados para la economía española: sólo por el 16\% de los encuestados (CIRES), y casi todos se decantan por los trabajadores temporales para la agricultura (14\%); por contra, los encuestados sí se muestran muy proclives $(65 \%)$ a la inmigración de técnicos profesionales y empresarios. En consecuencia, el número fijado en los cupos anuales se estima excesivo por un tercio de los encuestados y como «bastantes» por otro $45 \%$; sólo un $4 \%$ estima que tal oferta es escasa.

Aunque es opinión muy difundida en España que los inmigrantes desde paises menos desarrollados suelen realizar trabajos no deseados por los españoles, la competencia entre estos trabajadores inmigrados y los españoles menos cualificados parece clara para la mayoría de los encuestados: el 55\% opinan que los trabajadores inmigrados han contribuido a crear más paro entre los españoles (CIRES), aunque tal opinión ha disminuido respecto a $1992(62 \%)$ - , y un $38 \%$ creen que dichos trabajadores han contribuido a 
disminuir los salarios. Como es habitual, los españoles más «alarmados» son los de mayor edad, y también los que teóricamente entrarían en competencia laboral con estos inmigrantes, es decir los que tienen menos instrucción y los de posición social más baja.

Aunque sólo un $4 \%$ de los españoles encuestados trabaja en contacto con magrebíes, por lo que conocen opinan que las condiciones laborales de los inmigrantes son peores $(68 \%)$ que las de cualquier trabajador español que desarrolle las mismas funciones. Esta discriminación es, por supuesto, percibida con más claridad por los mismos inmigrantes, pues la denuncia el $74 \%$ de los marroquíes y el $72 \%$ de los senegaleses encuestados en la fachada mediterránea de España. Como signos de esta discriminación, los inmigrantes citan fundamentalmente la menor remuneración (43\%) y la dificultad en la obtención de contrato de trabajo (42\%), causas que coinciden plenamente con las señaladas por los españoles encuestados (CIS).

En las páginas que anteceden hemos resaltado los aspectos más problemáticos que los españoles perciben en sus relaciones con los inmigrantes magrebíes, quienes — como se indicó- son la colonia extranjera más numerosa en España y la que mantiene tasas de incremento más elevadas, generalmente alimentadas con inmigrantes en situación irregular. Dados los variados aspectos deficientes que muestran dichas relaciones, y las perspectivas de evolución de este colectivo, es preciso insistir en la necesidad de mejorar las actitudes de los españoles y en cuidar de modo especial la integración de estos inmigrantes, sobre todo si tenemos en cuenta que la percepción de las posibilidades de integración ha sufrido una evolución negativa: así, en el caso de los norteafricanos la percibían como problemática el 53\% de los encuestados en 1993 (CIRES), contra el 60\% en 1995. No obstante, la integración de los inmigrantes es valorada como necesaria por una amplísima mayoría de los españoles, aunque permanece un $15 \%$ de encuestados que se manifiestan contrarios, proporción que dobla a la de los que se declaran xenófobos.

En este sentido es preciso resaltar la orientación de la política de inmigración propugnada por el gobierno español. En efecto, hay que valorar el cambio acelerado - y en consecuencia sujeto a claroscuros- desde políticas seculares centradas sólo en la emigración, a las de inmigración establecidas recientemente. Así, la política de inmigración se inicia con la Ley de Extranjería de 1985 que cortó la permisividad oficial de acceso y permanencia en España de los inmigrantes de países en vías de desarrollo; después de 1990 ha continuado un progresivo fortalecimiento policial en la frontera sur de España-Unión Europea, al mismo tiempo que se busca la integración de los inmigrantes ya residentes en España.

En efecto, la política de integración queda oficialmente definida y potenciada desde finales de 1994, cuando el gobierno de España aprueba el Plan para la integración social de los inmigrantes ${ }^{18}$, dirigido a los residentes en situación regular; este Plan fue diseñado para una duración de cuatro años. Junto a la integración social de los inmigrantes, el Plan también incide en la cooperación para el desarrollo de los países emisores de inmigrantes, y en el conocimiento de los flujos migratorios. Aunque el Plan es de iniciativa gubernamental, se apoya en las administraciones autonómicas y municipales, así como en las organizaciones sociales y en las asociaciones de inmigrantes. Dentro de este Plan, durante 1995 se crearon el Foro para la Integración Social de los Inmigrantes -órgano para la consulta y diálogo entre Administraciones, organizaciones sociales y asociaciones de

18 Ministerio de Asuntos Sociales. D.G. de Migraciones, Plan para la integración social de los inmigrantes, Madrid, 1995, 71 pp.; el Plan fue aprobado en Consejo de Ministros el 2-12-1994. 
inmigrantes - y el Observatorio Permanente de la Inmigración —-macrosistema de información y estudios-. En 1996 (BOE de 23-02-1996) se publicó un nuevo Reglamento de ejecución de la Ley de Extranjería (1985), consensuado entre las partes implicadas, que facilita la permanencia e integración de los inmigrantes que ya residen en España. El nuevo Gobierno (1996) en principio no ha variado la orientación de esta política, amplísimamente aceptada entre los españoles, lo que sin duda es una adecuada «introducción» de futuro. 